\title{
BMJ Open Dabigatran persistence and adherence in New Zealand: a nationwide retrospective observational study
}

\author{
Paul Harper, Daryl Pollock, Matt Stephens
}

To cite: Harper P, Pollock D, Stephens M. Dabigatran persistence and adherence in New Zealand: a nationwide retrospective observational study. BMJ Open 2018;8:e020212. doi:10.1136/ bmjopen-2017-020212

- Prepublication history for this paper is available online. To view these files, please visit the journal online (http://dx.doi org/10.1136/bmjopen-2017020212).

Received 28 0ctober 2017 Revised 15 February 2018 Accepted 19 February 2018
Check for updates

Clinical Haematology, Palmerston North Hospital, Palmerston North, New Zealand

Correspondence to Dr Paul Harper; paul.harper@midcentraldhb. govt.nz

\begin{abstract}
Objective To determine the effect of age and gender on persistence and adherence in patients taking dabigatran for atrial fibrillation.

Design A retrospective observational study over 4 years using refill prescription data from the National Pharmaceutical Database.

Setting All patients in New Zealand who received dabigatran from July 2011 to September 2015.

Population 43339 people filled at least one prescription of dabigatran.

Main outcome measures The proportion of patients with good adherence (treatment available at least $80 \%$ of the time), and the proportion at risk of thrombosis (a break in treatment of more than 2 days) measured 6 -monthly for 3 years. Medication persistence recorded over 3 years.

Results Persistence was highest in older patients and showed a significant correlation with age $(p<0.001) ; 24 \%$ over 70 years had discontinued treatment by 6 months compared with $50 \%$ under 50 years. Adherence was highest in the elderly $(p<0.001)$ with $90 \%$ of patients over 80 years with good adherence at 12 months compared with $70 \%$ in patients aged $50-60$ years and less than $60 \%$ in those under 50 years. The time at risk of thrombosis showed a similar pattern with $25 \%$ below 60 years with inadequate anticoagulation more than $20 \%$ of the time. Adherence dropped during the first 18 months of treatment with the most marked fall in those under 50 years. Adherence shows that breaks in treatment are common with $30 \%$ of men under 60 years with a break in treatment of at least 28 days during the first 12 months. Conclusion Adherence and persistence correlate with the patient's age. Those over 70 years have high adherence consistent over time whereas younger patients have significantly worse adherence which declines over the first 18 months, with the lowest rate in those under 50 years. Adherence in our study is lower than reported in clinical trials, therefore the benefit of dabigatran in stroke prevention may not be realised in clinical practice especially in younger patients.
\end{abstract}

\section{INTRODUCTION}

The direct oral anticoagulants (DOACs) have been used in clinical practice for several years. In large randomised studies, they have been shown to be at least as effective as warfarin in the prevention of stroke associated with atrial fibrillation ${ }^{1}$ and in the management

\section{Strengths and limitations of this study}

This is the largest reported study of persistence and adherence to dabigatran and includes all patients (over 40 000) who received dabigatran since the introduction of the medication in New Zealand.

- The prescription data are accurate and complete, taken from the National Pharmaceutical Database; a record of all prescriptions issued in New Zealand.

- Dabigatran is dispensed monthly providing many data points for each patient.

- Refill prescription data have limitations; it can overestimate adherence and measuring gaps in treatment, is inexact and does not show precisely when treatment was taken between prescriptions.

- Persistence data were not censored for patients who died or for patients who changed to warfarin during the study period.

of acute thromboembolic disease. ${ }^{2} 3$ One potential advantage of the DOACs is that they have a fixed dose regimen and do not require regular monitoring. However, this perceived convenience has raised speculation that the lack of regular monitoring may be detrimental and lead to poorer drug adherence. This is of importance in the case of the DOACs as these drugs have a short half-life and strict adherence is necessary to maintain adequate anticoagulation; a break in treatment can rapidly decrease their efficacy. ${ }^{45}$

Adherence was reported at over $95 \%$ in the randomised clinical trials comparing dabigatran with warfarin, ${ }^{12}$ but the patients in these studies were closely supervised, and it is well recognised that similar levels of adherence are not seen in clinical practice. Adherence as low as $50 \%$ has been reported for antihypertensives and other cardiac medications, ${ }^{6}$ and two studies have reported dabigatran adherence rates lower than those seen in clinical trials, however these were relatively small studies and only measured adherence over 12 months. ${ }^{78}$ The aim of our study was to assess persistence and adherence to dabigatran in a larger unselected population over 3 years 
to determine if the duration of treatment had an impact on adherence. We also evaluated adherence by age and gender as previous studies have reported that adherence is higher in older patients, ${ }^{9}$ and women have poorer adherence than men for most cardiac medications. ${ }^{10}$

Dabigatran was introduced into clinical practice on 1 July 2011, and no prescriptions for this medication were issued prior to this date. It was fully subsidised so patients only pay the standard prescription charge for treatment. There were no limitations on prescribing; however, the drug was only approved by the New Zealand Medicines Safety Authority (MedSafe) for the prevention of stroke in non-valvular atrial fibrillation and as prophylaxis for orthopaedic surgery. Approval was widened in July 2014 to include the treatment of venous thromboembolic disease (VTE). There is no other funded DOAC available in New Zealand; the only alternative to dabigatran is warfarin. A key advantage of assessing adherence in the New Zealand population is the availability of complete and accurate data. All patients have a unique National Health Index number and data for all prescriptions issued are recorded in the National Pharmaceutical Database, allowing us to collect a complete dataset.

\section{METHODS}

\section{Data source}

Data were collected from the Ministry of Health pharmaceuticals database from 1 July 2011 to 30 September 2015. Data on all prescriptions issued in New Zealand are recorded in the pharmaceutical database. The following information was obtained for each dabigatran prescription during the study period; the date the medication was dispensed, the patient's national identification number (encrypted), the patient's gender and age at time of dispensing, the number of tablets dispensed and the tablet formulation ( $75 \mathrm{mg}, 110 \mathrm{mg}$ or $150 \mathrm{mg}$ ).

\section{Episodes of treatment}

An episode of treatment was defined as the time from the date of the first prescription to the date of the last prescription. If the interval between two prescriptions was more than 12 months, the patient was assumed to have discontinued treatment and restarted a new episode of treatment. Our assessment of drug persistence and drug adherence are based on the total number of episodes of treatment.

\section{OUTCOME MEASURES}

\section{Dabigatran persistence}

Persistence was defined as the duration of time each patient remained on treatment. It was calculated as the number of days between the first prescription and last prescription plus the number of days of treatment issued at the last refill. Patients were assumed to still be taking treatment if a prescription was filled within the last 2 months of the study period. A Kaplan-Meier survival analysis was used to calculate persistence over time.

The aim was to report persistence in patients on longterm treatment for atrial fibrillation, therefore patients were excluded from the analysis if (1) their prescription data suggested they were on treatment for prophylaxis; namely those with a single prescription for less than 28 days or for $220 \mathrm{mg}$ once daily for 15-35 days (orthopaedic prophylactic dose), or (2) if they started treatment after 1 August 2014 to exclude patients who may have received short-term treatment for Venous thromboembolic disease (VTE).

\section{Calculating drug adherence}

Adherence was defined as the extent to which the patient took medication as prescribed while on treatment. Refill prescription data were used to evaluate adherence. Data from the national database provided precise data on the number of capsules dispensed to each patient with each prescription. This enabled us to calculate drug adherence using the number of capsules available and the time interval between prescriptions. A gap in treatment was defined as any period where the patient had insufficient medication to take dabigatran twice daily up to the date of the next prescription (figure 1). It was assumed that patients restarted treatment on the day they received their next prescription. Adherence was calculated using the proportion of days treatment was available and was calculated for both men and women in five age groups: <50 years, $50-60$ years, $60-70$ years, $70-80$ years and $>80$ years.

For each age group, we calculated the proportion of patients with $100 \%$ adherence (full adherence); that is sufficient medication to cover the whole period with no breaks in treatment, and $80 \%$ adherence (good adherence); that is sufficient medication to cover at least $80 \%$ of the days for the specified treatment period.

Adherence was calculated at 6-monthly intervals using data from all patients on treatment for at least the specified time (eg, 12 months adherence included all patients on treatment for at least 12 months). Adherence was calculated up to 36 months.

\section{Calculated days at risk}

The adherence data include all breaks in treatment, however a short break of 2 days or less is unlikely to put a patient at risk of thrombosis as the half-life of the drug is approximately 12 hours. Therefore, we have calculated the time a patient is at risk by measuring the proportion of time a patient does not have treatment available, excluding short breaks of 2 days or less and the first 2 days of any break in treatment as illustrated in figure 1 . This was measured at 6-monthly intervals.

\section{Breaks in treatment}

The total number of breaks and length of each break were recorded for each patient during the first 12 months. 


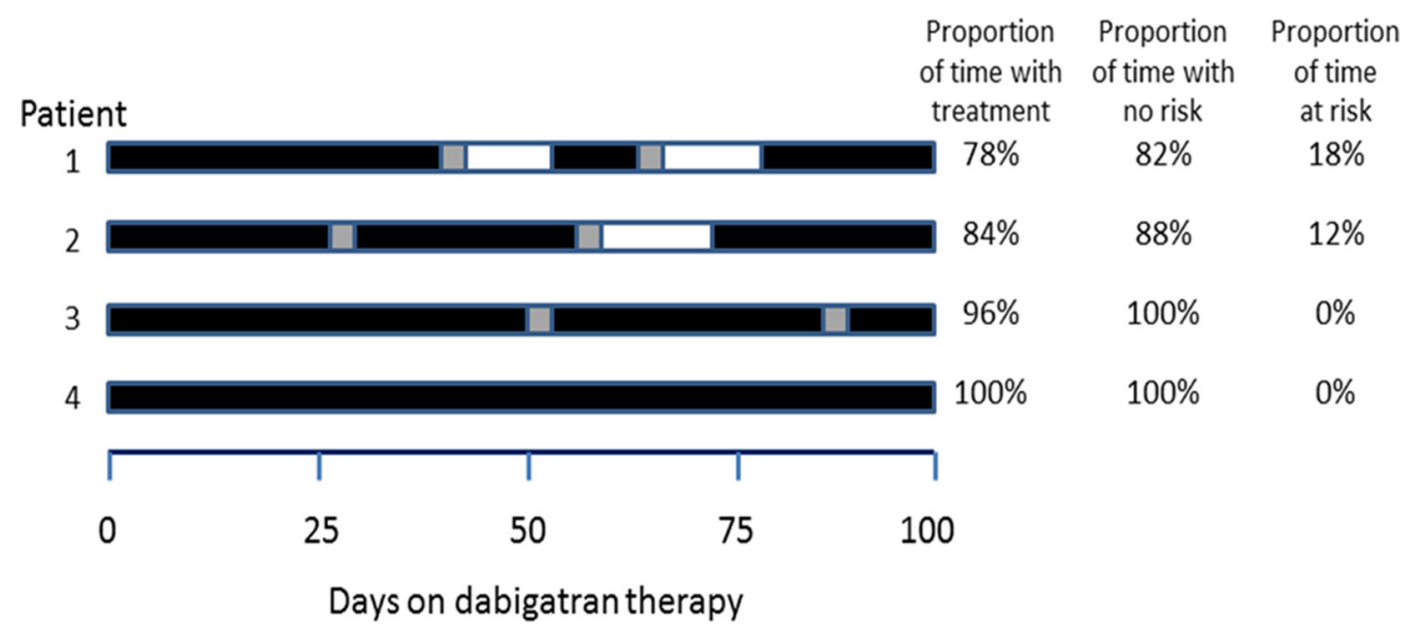

Figure 1 Examples of dabigatran treatment history for four patients. The solid blocks indicate periods when dabigatran would be available. The grey squares represent breaks in treatment of 2 days, when the patient is not at risk. The white blocks represent periods when treatment is not available and the patient is at increased risk.

\section{STATISTICAL ANALYSIS}

Data were analysed using SPSS software (V.24, IBM, 2016), a Kaplan-Meier survival analysis was used to determine if age or gender varied significantly in patients' probability of continuing treatment, while a binary logistic linear mixed model (first order autoregressive working correlation matrix) was used to determine the significance of any change over time for age or gender for the risk or adherence outcome variables.

\section{RESULTS}

\section{Study population}

A total of 43339 patients received at least one prescription of dabigatran during the 51-month study period. The median age of patients on dabigatran was 72 years (male 70 years, female 74 years) with $58.7 \%$ male. More patients were started on $110 \mathrm{mg}(51 \%)$ than $150 \mathrm{mg}$ dose and significantly larger proportion of women (59.6\%) were started on the low dose compared with men $(45.4 \%)$ (table 1) $(\mathrm{p}<0.001)$. The patients started on the $110 \mathrm{mg}$ dose were substantially older (median 78 years) than those taking $150 \mathrm{mg}$ dose (median 65 years).

\section{Episodes of treatment}

A total of $1277(2.9 \%)$ patients had one break in treatment of more than 12 months and $29(0.1 \%)$ patients had two breaks; a total of 44674 episodes of treatment were included in the analysis of drug persistence and adherence.

\section{Dispensing data}

Dabigatran is largely dispensed monthly in New Zealand; $92 \%$ of refills were for a period of 1 month ( 56 or 60 tablets), $1 \%$ for 2 months and $2 \%$ for 3 months, the remainder were dispensed for a period of less than 1 month. In all cases the total number of tablets dispensed was recorded; a total of 43 million tablets have been dispensed. Three tablets sizes are available in New Zealand ( $75 \mathrm{mg}, 110 \mathrm{mg}$ and $150 \mathrm{mg}$ ).

\section{Medication persistence}

Only 336 prescriptions met the criteria for orthopaedic or surgical prophylaxis and these were removed from further analysis. Dabigatran was registered for the treatment of VTE from 1 August 2014, therefore all patients who started treatment after this date were excluded as some patients may intentionally be on short-term treatment. All remaining patients (30 788) in our series who started treatment between 1 July 2011 and 31 July 2014 were included in the analysis as they were assumed to be

\begin{tabular}{|c|c|c|c|}
\hline & Male & Female & Total \\
\hline $\begin{array}{l}\text { Number of } \\
\text { patients (\%) }\end{array}$ & $25445(58.7)$ & $17894(41.3)$ & 43339 \\
\hline $\begin{array}{l}\text { Median age, } \\
\text { years }\end{array}$ & 70 & 74 & 72 \\
\hline \multicolumn{4}{|c|}{ Age groups, \% (n) } \\
\hline$<50$ years & $6.4(1638)$ & $4.2(752)$ & $5.5(2390)$ \\
\hline 50-60 years & $13.0(3310)$ & $8.1(1447)$ & $11.0(4757)$ \\
\hline $60-70$ years & $27.4(6985)$ & $21.4(3835)$ & $25(10$ 820) \\
\hline 70-80years & $33.2(8469)$ & $35.3(6323)$ & 34.1 (14 792) \\
\hline$>80$ years & $19.8(5043)$ & $30.9(5537)$ & $24.4(10580)$ \\
\hline \multicolumn{4}{|l|}{ Dose, ${ }^{*} \%(n)$} \\
\hline $150 \mathrm{mg}$ & $53.6(13634)$ & $38.5(6887)$ & $47.3(20521)$ \\
\hline $110 \mathrm{mg}$ & $45.4(11541)$ & 59.6 (10 669) & $51.2(22210)$ \\
\hline $75 \mathrm{mg}$ & $1.1(270)$ & $1.9(338)$ & $1.4(608)$ \\
\hline $\begin{array}{l}\text { Number of } \\
\text { treatment } \\
\text { episodes }\end{array}$ & 26268 & 18406 & 44674 \\
\hline
\end{tabular}

*Established maintenance dose (for patients who received a prescription for more than one dose, the maintenance dose is the dose they received for the longest period). 
Treatment started prior to August 2014

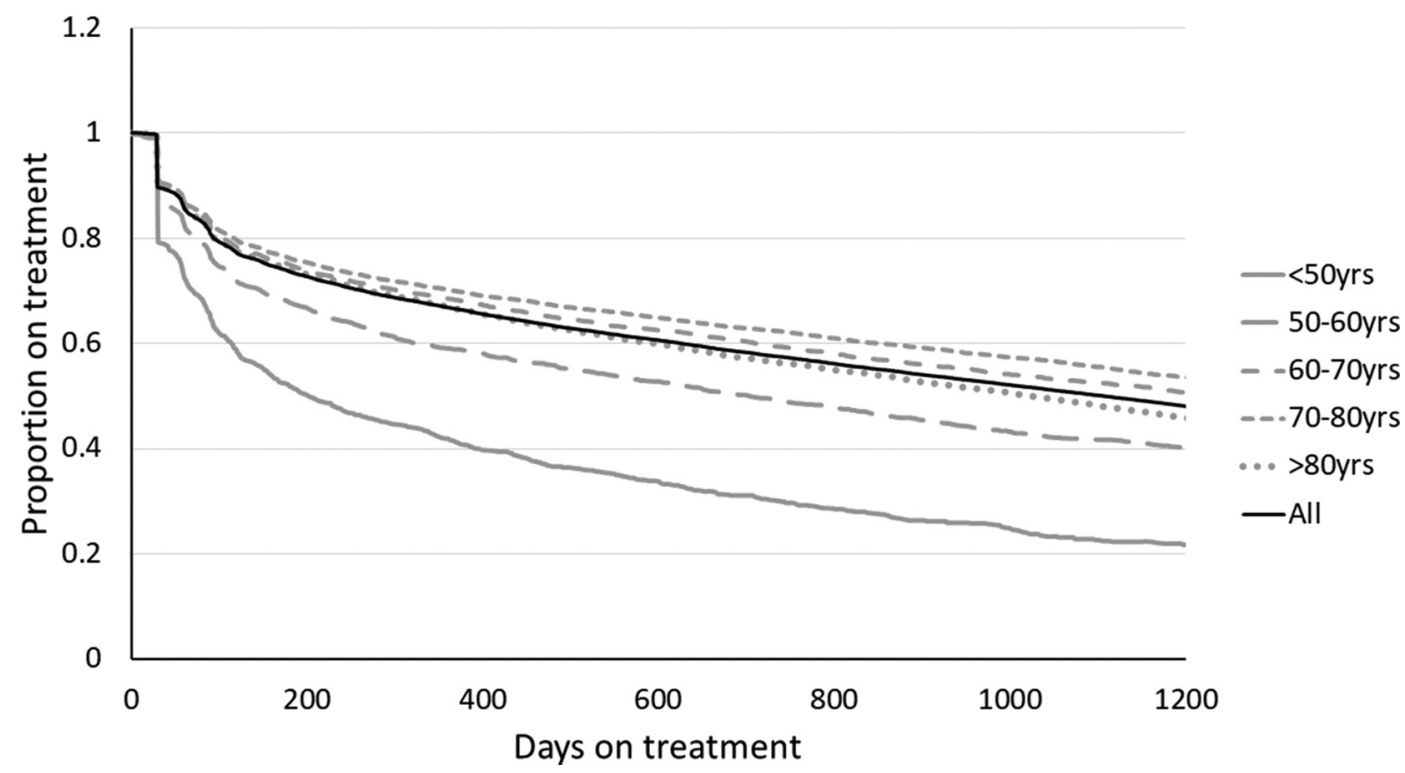

Figure 2 Dabigatran persistence.

on treatment for stroke prevention in non-valvular atrial fibrillation.

Although the patients with atrial fibrillation would be expected to remain on treatment long term, approximately $26 \%$ had discontinued treatment within 6 months; $10 \%$ only filled one prescription, a further $8 \%$ only filled two prescriptions and 19\% had stopped treatment by 3 months.

Persistence showed a significant correlation with age $(p<0.001)$ with the lowest persistence rate in those under 50 years with almost $50 \%$ stopping treatment within 6 months and $60 \%$ within 1 year. In the patients over 70 years, the persistence rate was significantly higher with over $70 \%$ continuing treatment after 12 months and 55\% on treatment at 3 years (figure 2 ).
Persistence data were not censored for patients who died during the study, the highest death rate would be expected in older patients and therefore may underestimate persistence in the older age groups. We have also not accounted for those patients who change to warfarin due to side-effects or other complications. In our series, approximately $6.5 \%$ of patients changed from dabigatran to warfarin and remained on warfarin long term.

\section{Adherence at 12 months}

Adherence was calculated on patients who started treatment prior to August 2014, and therefore only includes patients on treatment for stroke prevention in atrial fibrillation. A total of 20237 (45.3\%) patients remained on dabigatran treatment for at least 12 months and

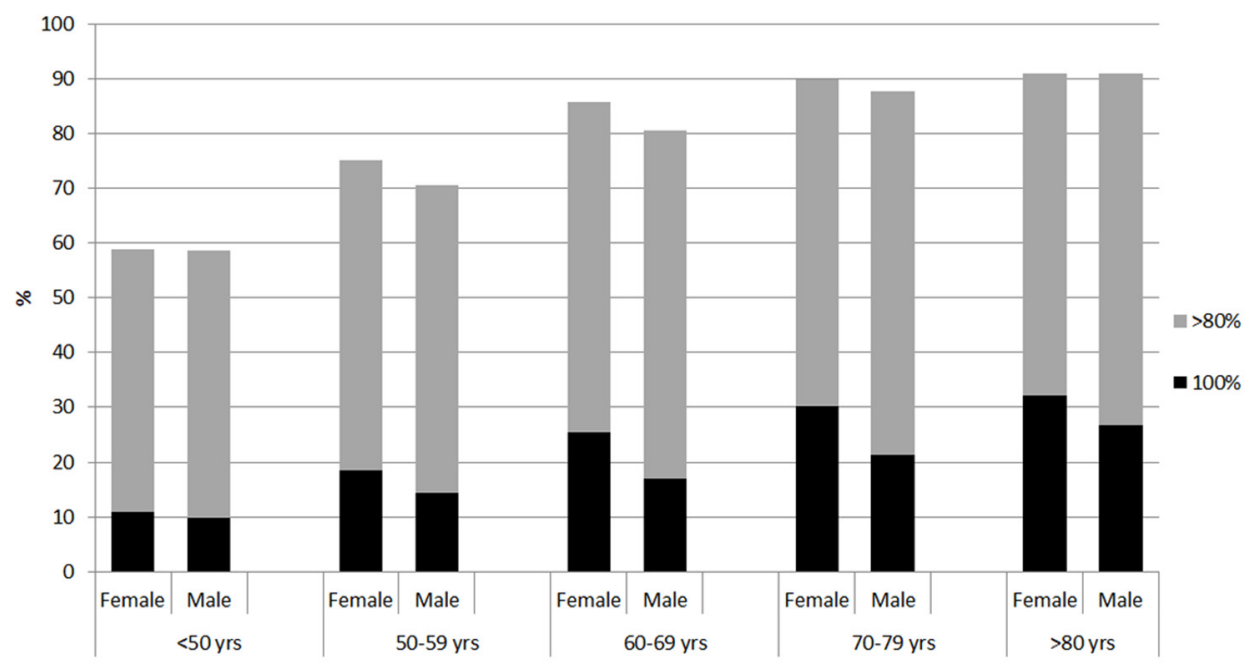

Figure 3 The percentage of patients with treatment available continuously (100\% adherence) and treatment available more than $80 \%$ of the time for each age group at 12 months for all patients who remained on treatment for at least 12 months $(n=20237)$. 


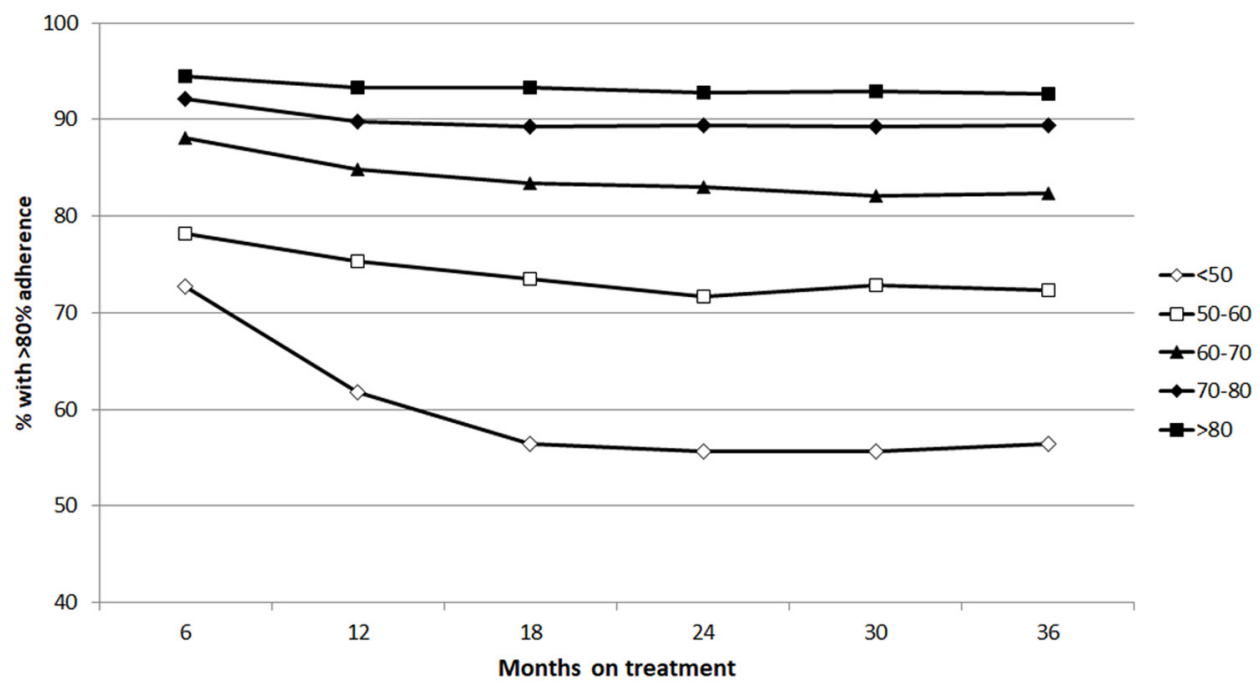

Figure 4 The proportion of patients with more than $80 \%$ adherence for each age group at 6 -monthly intervals for all patients on treatment for at least 30 months.

$84.8 \%$ had treatment available at least $80 \%$ of the time (good adherence). Adherence was significantly higher in females than males $(87.5 \%$ vs $83 \%, \mathrm{p}<0.001)$. Adherence showed a clear correlation with age $(p<0.001)$. The highest level of adherence was seen in patients over the age of 80 years with over $90 \%$ having good adherence and over $30 \%$ with treatment available continuously (full adherence). Adherence was similar in the patients aged $70-80$ years, but was progressively poorer in each age group below the age of 70 years. Adherence was worst in the patients below the age of 50 years where less than $60 \%$ had good adherence and less than 10\% had full adherence at 12 months (figure 3 ).

\section{Adherence over time}

Adherence was calculated at 6-monthly intervals in all patients who remained on treatment for at least 30 months
(10119 patients) (figure 4). There were significant differences over time in $80 \%$ adherence rate $(p<0.001)$. Adherence remains consistent over time in older patients (over 70 years), but falls during the first 12-18 months in younger patients. Adherence drops to a level of $72 \%$ in patients aged $50-60$ years and falls below $60 \%$ in patients under the age of 50 years.

\section{Days at risk}

An alternative method of assessing treatment is to measure the proportion of time patients are at risk of thrombosis. We have assumed that patients have a low risk of thrombosis if treatment is missed for 2 days but a break in treatment for a longer period would lead to inadequate anticoagulation. Figure 5 shows that approximately $40 \%$ of patients over the age 70 years have no risk of thrombosis during the first 12 months of treatment and a further $45 \%$ have less than

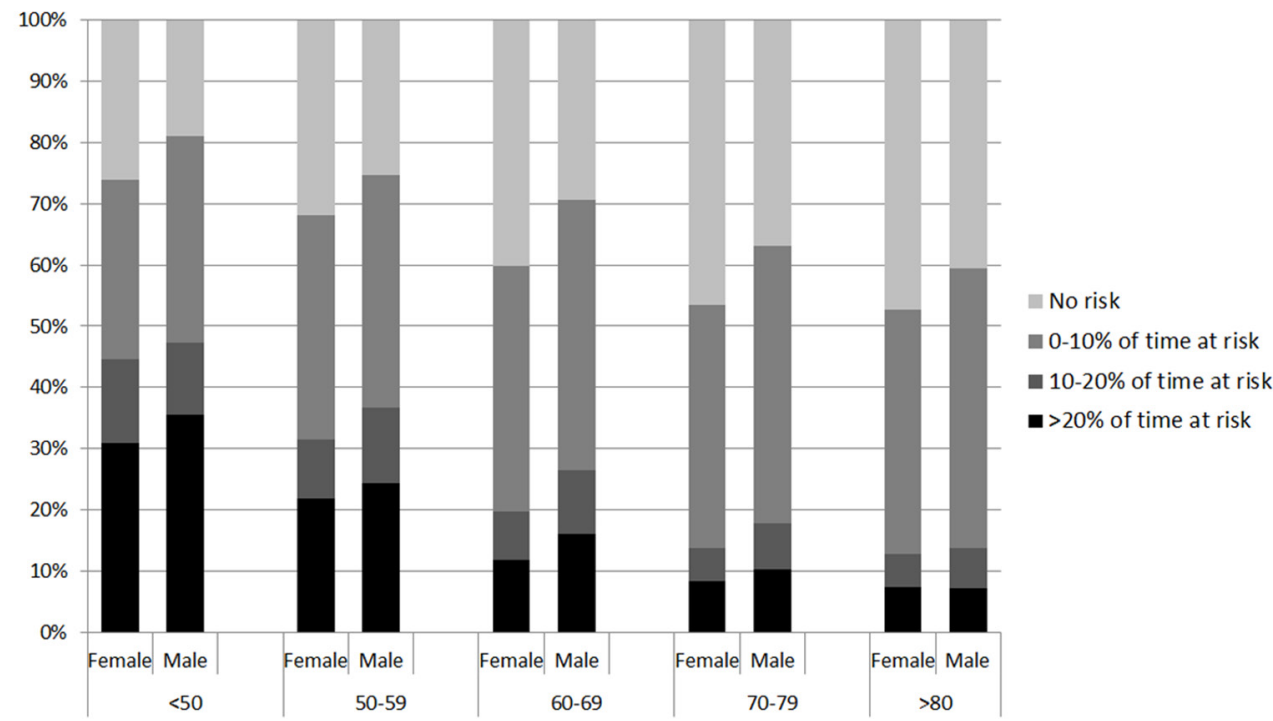

Figure 5 The proportion of patients with no risk, $0 \%-10 \%$ of the time at risk, $10 \%-20 \%$ of the time at risk and more than $20 \%$ of the time at risk during the first 12 months of treatment for all patients who remained on treatment for at least 12 months $(n=20237)$. 


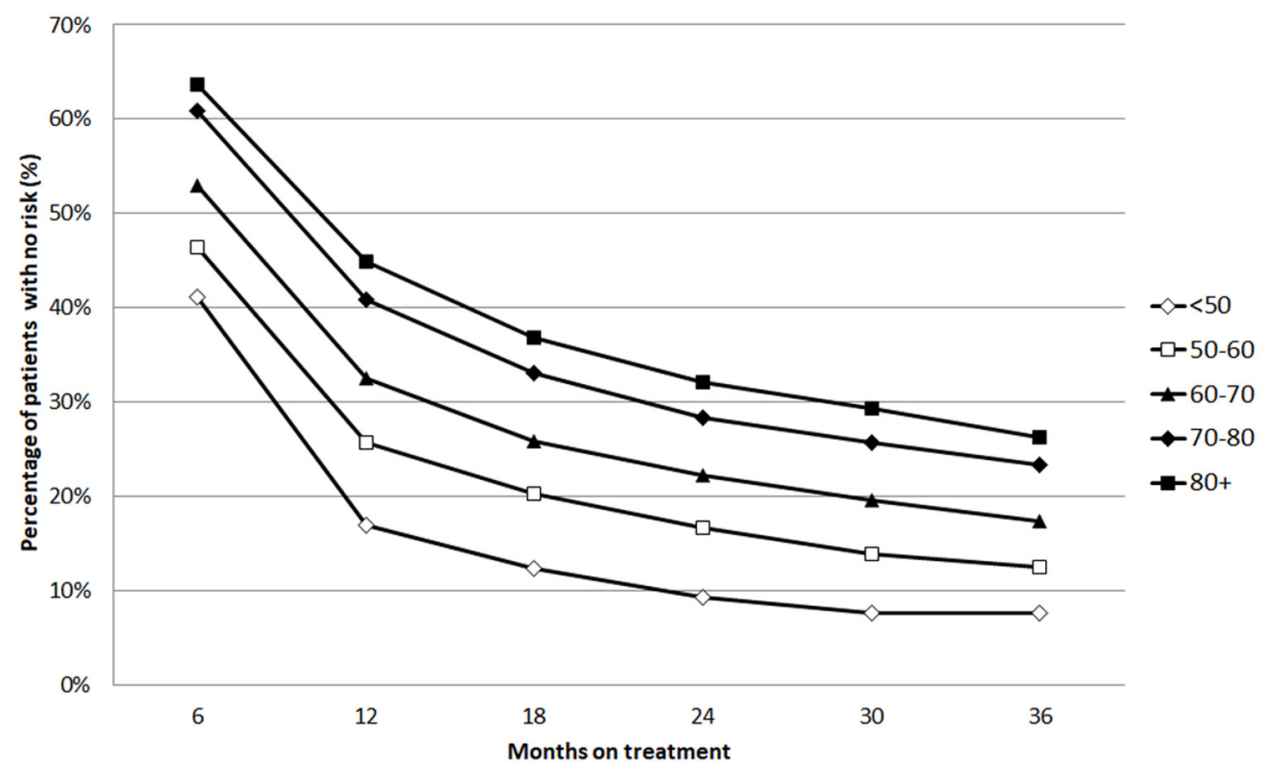

Figure 6 Percentage of patients with no risk of thrombosis at 6-monthly intervals.

$10 \%$ of the time at risk. In patients under 60 years, however, approximately $25 \%$ of patients are at risk of thrombosis more than $20 \%$ of the time and less than $25 \%$ have no risk. Age showed a significant correlation with the time at risk (at risk vs no risk: $\mathrm{p}<0.001)$.

\section{Risk over time}

The percentage of patients at risk increases over time; in the patient group with the best adherence, namely those over 80 years, $30 \%$ had no risk of thrombosis during the first 2 years and in those under 50 years, only $10 \%$ had no risk (figure 6 ).

\section{Patterns of adherence}

Patterns of adherence were inconsistent. Figure 7 shows various patterns of adherence for a selection of 100 male patients under the age 60years. This shows that breaks in treatment are variable with some patients having frequent short breaks whereas others have prolonged periods off treatment. To summarise this, we have calculated the proportion of patients with a break in treatment of at least 2 days, 7 days, 14 days and 28 days during their first 12 months of treatment (figure 8 ). This shows that at least $30 \%$ of male patients under the age of 60 years have at least one break of more than 28 days during the first 12 months of treatment.

\section{DISCUSSION}

The principal finding of our study is that the patient's age has a significant impact on how reliably medication

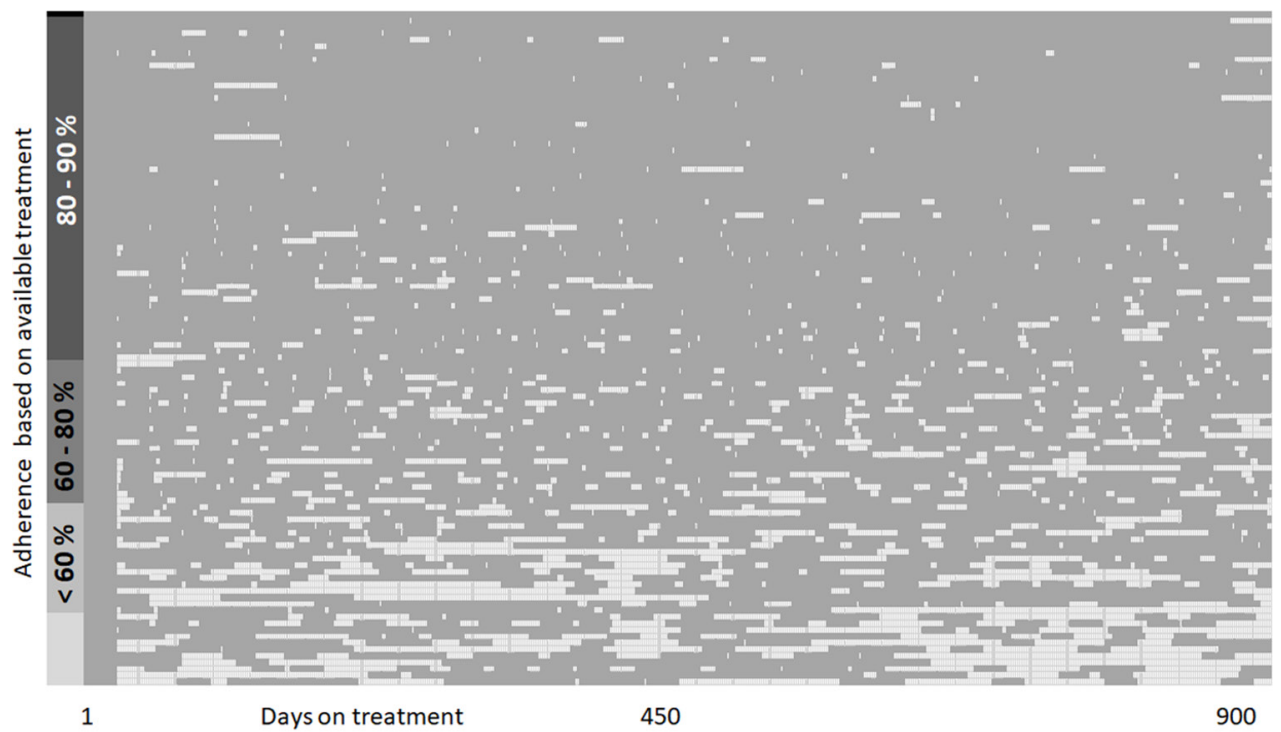

Figure 7 Pattern of adherence for 100 male patients under the age of 60 years on dabigatran for at least 900 days. Each row represents a single patient. The grey boxes represent the time when the patients had treatment available and the white boxes represent period without treatment. The patient on the top row has $100 \%$ adherence. 


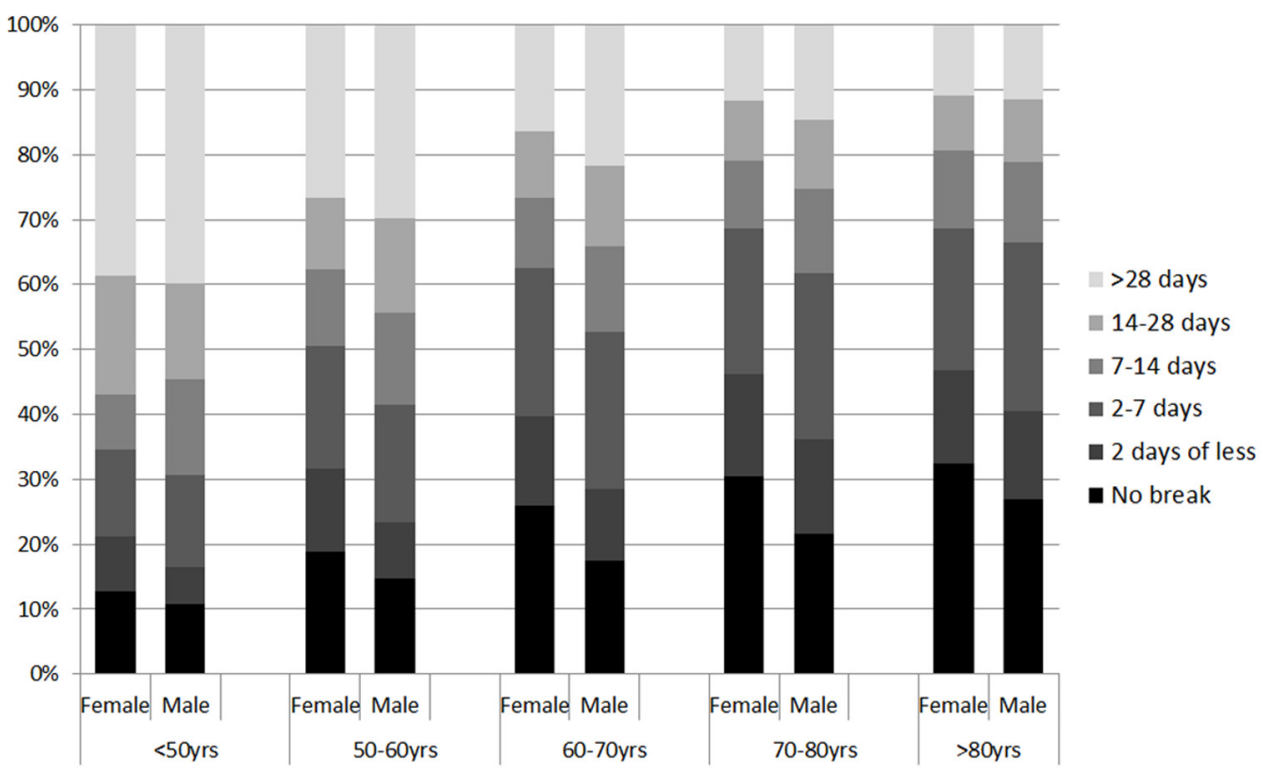

Figure 8 The proportion of patients with no breaks in treatment, a break of 2 days or less, 2-7 days, 7-14 days, 14-28 days or more than 28 days, during the first 12 months of treatment for patients on treatment for at least 12 months ( $n=20237$ ).

is taken, with the lowest rates of drug persistence and adherence in patients under the age of 50 years. Dabigatran is prescribed as a long-term medication and even in the most compliant group, over a quarter of patients have stopped treatment by 6 months and only $70 \%$ remain on treatment at 1 year. In patients under 50 years the rate is significantly worse with almost half discontinuing within 6 months (figure 2). Adherence shows a similar correlation with age. In patients over 70 years, adherence rates are high with over $90 \%$ with good adherence at 12 months which remained consistent over 3 years. In contrast, patients below the age of 70 years had lower adherence which was most marked in those below the age of 50 years (70\% adherent) and showed a steady decline over the first 2 years of treatment (figures 3,4). Our results also show that breaks in treatment are common (figure 8) and do not follow any pattern (figure 7); $30 \%$ of patients under the age of 60 years had a break in treatment of more than 28 days during the first 12 months of treatment. An unexpected finding was the better adherence in women which is not the case with most cardiac drugs.

The main concern with poor adherence to anticoagulants is the risk of thrombosis. Ideally for the greatest benefit treatment should be continuous but in practice only a small proportion of patients achieve this; in our series only $30 \%$ in the most adherent group and $13 \%$ of men under 60 years, collected sufficient medication (12 prescriptions on time) to be fully adherent during the first 12 months of treatment. A more meaningful measure for dabigatran is to assess the proportion of time the patient is without adequate anticoagulation and therefore at risk of thrombosis. Based on the assumption that a break in treatment of less than 2 days is unlikely to put a patient at risk, we found that $50 \%$ of patients over 70 years had no risk of thrombosis during the first
12 months of treatment, whereas in those under 50 years only $25 \%$ had no risk (figure 5 ).

The strength of our study is that it includes all patients starting dabigatran in New Zealand since the drug was introduced and gives us a picture of adherence over 3 years. The analysis is based on refill prescription rates, which is regarded as a valid accurate assessment of adherence $^{11}$ and the existence of a National Pharmaceutical Database allowed us to collect complete accurate data for over 40000 patients. Smaller studies have reported similar rates of adherence at 1 year $(72.2 \%$ in a US study and $76.8 \%$ in a Danish study), but did not have sufficient data to report changes in adherence over time. ${ }^{67}$ These results and our own data show that adherence rates for dabigatran are good compared with other cardiac medications, especially for a twice daily drug. A meta-analysis of 20 observational studies of adherence to cardiac drugs reported that up to $50 \%$ of patients do not take their medication as prescribed ${ }^{12}$ and a similar estimate has been reported by the WHO. ${ }^{13}$ The dosing frequency also has an impact on adherence with lower rates reported for medications taken twice daily compared with a once daily regimen. $^{14}$

Our study has some limitations. Refill prescription data tend to overestimate adherence as they show the proportion of time the patient has medication available, but not if it was taken. Also measuring gaps in treatment is inexact and does not show precisely when treatment was taken between prescriptions.

There are many potential reasons for poor dabigatran adherence including twice daily dosing, gastric side-effects, and polypharmacy, but it is difficult to identify any specific factor that explains the difference between younger and older patients. There is evidence that patients with a previous event such as a stroke or transient 
ischaemic attack are more likely to be adherent ${ }^{6}$ and these tend to be older. Also, the elderly have more frequent contact with healthcare professionals and a proportion will be in supervised care with strict routines for administering medication. In contrast, younger patients have less contact with healthcare professionals and may perceive no immediate benefit from their treatment as they are asymptomatic and are on preventative treatment for what they see as a rare complication.

The impact of poor adherence on clinical outcomes is difficult to measure. Although adherence rates are relatively high for dabigatran, the rate reported in younger patients in our study is substantially lower than those reported in the randomised clinical trials that led to the registration of dabigatran; the Randomized Evaluation of Long-Term Anticoagulation (Therapy) RELY study reported an adherence of 95\% and the RECOVER study of $98 \% .{ }^{12}$ The difference between these rates and those in our series emphasises the difficulty extrapolating clinical outcomes from randomised clinical trials to everyday clinical practice, and raises concerns that the reduction in the risk of stroke expected from the results of the RELY study, may not be realised in practice.

\section{CONCLUSION}

In general, dabigatran adherence is high compared with other chronic medications particularly in older patients, however our results show a clear correlation with age with significantly worse adherence in patients under the age of 60 years. Identifying this subgroup is important as they are at increased risk of stroke and therefore it may be appropriate to target further education ${ }^{15}$ to these patients to ensure that they have a clear understanding of the importance of taking medication regularly.

Acknowledgements We acknowledge the assistance of Brendan Stephenson, Statistician, Massey University, Palmerston North, for statistical analysis, and Analytical Services, The Ministry of Health for provision of the pharmaceutical database data.

Contributors PH: designed the study, prepared ethics application, collected data from Ministry of Health, analysed data (with statistician) and prepared the manuscript. MS: assisted with study design, review of data and development and review of the manuscript. DP: assisted with data collection and review of manuscript. PH, lead author, affirms that the manuscript is an honest, accurate and transparent account of the study being reported; that no important aspects of the study have been omitted; and that any discrepancies from the study as planned have been explained.

Funding The study was funded from within department funds. There was no commercial support for the study.

Competing interests All authors have completed the ICMJE uniform disclosure form for competing interests. PH is a director of INR Online Ltd, an online warfarin management software company.
Patient consent Not required.

Ethics approval The study was approved by the New Zealand Health and Disability Ethics Committee (ref: 14/CEN/135/AM01).

Provenance and peer review Not commissioned; externally peer reviewed.

Data sharing statement Prescription data can be requested from the Ministry of Health in New Zealand. Data were released to the authors under ethics approval. Further approval may be required to share data.

Open Access This is an Open Access article distributed in accordance with the Creative Commons Attribution Non Commercial (CC BY-NC 4.0) license, which permits others to distribute, remix, adapt, build upon this work non-commercially, and license their derivative works on different terms, provided the original work is properly cited and the use is non-commercial. See: http://creativecommons.org/ licenses/by-nc/4.0/

(C) Article author(s) (or their employer(s) unless otherwise stated in the text of the article) 2018. All rights reserved. No commercial use is permitted unless otherwise expressly granted.

\section{REFERENCES}

1. Connolly SJ, Ezekowitz MD, Yusuf S, et al. Dabigatran versus Warfarin in Patients with Atrial Fibrillation. N Engl J Med Overseas Ed 2009;361:1139-51.

2. Schulman S, Kearon C, Kakkar AK, et al. Dabigatran versus warfarin in the treatment of acute venous thromboembolism. N Engl J Med 2009;361:2342-52.

3. López-López JA, Sterne JAC, Thom HHZ, et al. Oral anticoagulants for prevention of stroke in atrial fibrillation: systematic review, network meta-analysis, and cost effectiveness analysis. BMJ 2017;359:j5058.

4. Rodriguez RA, Carrier M, Wells PS. Non-adherence to new oral anticoagulants: a reason for concern during long-term anticoagulation? J Thromb Haemost 2013;11:390-4.

5. Ten Cate $\mathrm{H}$. Monitoring new oral anticoagulants, managing thrombosis, or both? Thromb Haemost 2012;107:803-5.

6. Newby LK, LaPointe NM, Chen AY, et al. Long-term adherence to evidence-based secondary prevention therapies in coronary artery disease. Circulation 2006;113:203-12.

7. Gorst-Rasmussen A, Skjøth F, Larsen TB, et al. Dabigatran adherence in atrial fibrillation patients during the first year after diagnosis: a nationwide cohort study. J Thromb Haemost 2015;13:495-504.

8. Shore S, Carey EP, Turakhia MP, et al. Adherence to dabigatran therapy and longitudinal patient outcomes: insights from the veterans health administration. Am Heart J 2014;167:810-7.

9. Krueger K, Botermann L, Schorr SG, et al. Age-related medication adherence in patients with chronic heart failure: A systematic literature review. Int J Cardiol 2015;184:728-35.

10. Manteuffel M, Williams S, Chen W, et al. Influence of patient sex and gender on medication use, adherence, and prescribing alignment with guidelines. J Womens Health 2014;23:112-9.

11. Steiner JF, Prochazka AV. The assessment of refill compliance using pharmacy records: methods, validity, and applications. J Clin Epidemiol 1997;50:105-16.

12. Naderi SH, Bestwick JP, Wald DS. Adherence to drugs that prevent cardiovascular disease: meta-analysis on 376,162 patients. Am J Med 2012;125:882-7.

13. Sabate E. World Health Organization. Adherence to long-term therapies: evidence for action. 2003 http://www.who.int/chp/ knowledge/publications/adherence_introduction.pdf (Cited 25 Aug 2017).

14. Coleman $\mathrm{Cl}$, Limone $\mathrm{B}$, Sobieraj DM, et al. Dosing frequency and medication adherence in chronic disease. J Manag Care Pharm 2012;18:527-39.

15. Brown TM, Siu K, Walker D, et al. Development of a conceptual model of adherence to oral anticoagulants to reduce risk of stroke in patients with atrial fibrillation. J Manag Care Pharm 2012;18:351-62. 